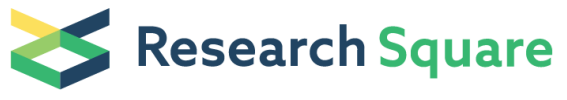 \\ Preprints are preliminary reports that have not undergone peer review. \\ They should not be considered conclusive, used to inform clinical practice, or referenced by the media as validated information.
}

\section{Patent landscape of Chinese Classical Formulas}

\author{
Ruipeng Shi \\ University of Macau Institute of Chinese Medical Sciences \\ Hua Luo \\ University of Macau Institute of Chinese Medical Sciences \\ Yi Zhao \\ University of Macau Institute of Chinese Medical Science \\ Yuyang Tang \\ University of Macau Institute of Chinese Medical Sciences \\ Zhangfeng Zhong \\ University of Macau Institute of Chinese Medical Sciences

\section{Shengpeng Wang} \\ University of Macau Institute of Chinese Medical Sciences \\ Yuanjia Hu ( $\square$ yuanjiahu@umac.mo) \\ University of Macau https://orcid.org/0000-0001-5244-8577
}

\section{Research}

Keywords: Chinese classical formulations, Chinese medicine, patent, product transformation

Posted Date: October 29th, 2021

DOI: https://doi.org/10.21203/rs.3.rs-1009737/v1

License: (c) (i) This work is licensed under a Creative Commons Attribution 4.0 International License. Read Full License 


\section{Abstract}

Background

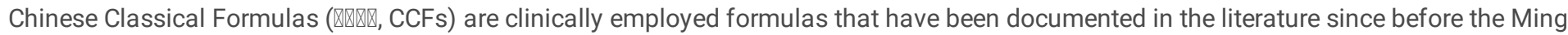
era. In 2010, China began focusing on the development and product transformation of CCFs and issued a list of 100 CCFs as a reference. Patents are key components of the process for transferring technology to product; however, they are rarely employed in current CCF research. Therefore, the present study aims to explore the current situation of CCFs based on the China National Intellectual Property Administration (CNIPA) and provide a reference for researchers, investors, and policymakers to make relevant decisions.

Methods

Information on CCF publication numbers was obtained from the CNIPA, and data for patent applications made before June 30, 2021, on inventors, titles, and abstracts were searched in the patent database, Derwent Innovation. Duplicate application numbers were removed, applications were standardized, and inventors were categorized. The processed data were then used for subsequent analyses.

Results

A total of 287 patents were included in this analysis, and 61 CCFs were patented. Two major policies regarding CCFs in 2011 and 2019 greatly stimulated related patent applications, but lacked sustainability, followed by a relatively large decline in 2012 and 2020 . Among the granted patents, $42.59 \%$ are analytical methods-related inventions and $24.07 \%$ for preparation methods. The percentage of core patents on substance basis and mechanism of action is relatively small.

Conclusion

Policies have a significant impact on CCF R\&D. The number of CCF patent applications is increasing every year and there is an increasing number of companies as patent applicants, which indicates that CCF is considered to have a good market potential. However, the lack of high quality patents may create difficulties for future development and this will be an important issue to be addressed. Keywords Chinese classical formulations, Chinese medicine, patent, product transformation

\section{Background}

Chinese medicine has made remarkable contributions to public health. Tu Youyou, the first Chinese Nobel Prize winner in physiology or medicine, identified a non-toxic extract of wormwood that induced a significant effect on parasite clearance (Plasmodium berghei and Plasmodium crabi) in a malaria model, which sparked the interest in Chinese medicine in numerous scientists worldwide [1, 2]. Chinese medicine has played a key role in the treatment of diseases for thousands of years before the advent of modern medicine [3], and countless formulations that have been used frequently over time have been recorded in ancient books, which include the varieties of herbs, dosages, preparation methods, and indications [4].

Chinese Classical Formulas (CCF) are clinically applied formulas that have been documented since the Qing Dynasty or even earlier and are commonly used in clinical practice, with clear and specific therapeutic purposes, features, and advantages [5]. In 2010, the Chinese government held an international symposium to discuss the secondary development of CCFs and the globalization of Chinese medicine [6]. On April 13, 2018, the Chinese government published the first selected 100 CCFs, which were gathered from 37 ancient medical works of literature [7], such as the Re Bing Lun and the Jin Kui Yao Lve. Preparations included 87 decoctions, 12 powders, and 1 ointment. Licorice was the most commonly utilized herb, which appeared in 60 CCFs. On June 1, 2018, simplified registration regulations were officially authorized,

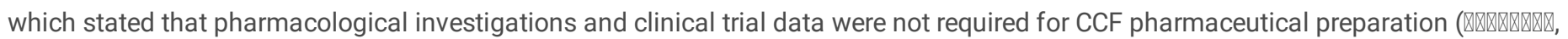
CCFPP) applications. This shortened the research cycle and saved CCF research and development costs [8]. Numerous corporations and research institutions have shown considerable interest in this 'green channel' for the development of CCFs.

Many scholars and enterprises were interested in the present state of CCF patents; however, limited research has been conducted in this field. Thus, this study aims to describe the basic situation of CCFs in the China National Intellectual Property Administration (CNIPA) from multiple aspects, such as the number of patents, major inventors, and technology classifications, to reveal the research value of CCFs and provide a reference for researchers, investors, and policymakers for making relevant decisions.

\section{Methods}

From the list of 100 CCFs issued by the National Administration of Traditional Chinese Medicine, we obtained publication numbers and basic details of each patent by searching the CNIPA (www.cnipa.gov.cn). In addition, Derwent Innovation (www.derwentinnovation.com), which is a 
global supplier that provides accurate and high-quality patent documents, was used to create a dataset of CCF-related patents published before June 31, 2021. To capture the latest patent information, processing and expired patents were also included in our analysis. Publication numbers, publication years, inventors, titles, abstracts, and International Patent Classifications (IPCs) were considered. We first standardized the basic data by removing duplicate records caused by abbreviations or misspelling. Accordingly to the rules of preferred reporting items for systematic reviews and meta-analyses (PRISMA) [9].

The whole procedure included the following steps: 1) Patents with duplicate application numbers were manually excluded. 2) According to the current status of patent technologies in development, we categorized patent technologies into seven categories to show the technological advances of CCFs more clearly. When multiple technology types were present, we only maintained the most creative and protective types. CCF-related technologies were classified into seven categories, which included analytical methods, new indications, novel dosage forms, preparation methods, modified formulations, quality control methods, and equipment. 3) Patent names with subtle differences were harmonized. 4) Inventors were divided into three categories: universities/hospitals, enterprises, and individuals. 5) Finally, we used hotspot maps, line graphs, cumulative histograms, and matrices to comprehensively describe the evolution process and research status of CCF technologies according to data classification and technology labels.

\section{Results}

\section{Data cleaning and overview}

Patent families were defined as patents of the same invention submitted in different regions. In this study, we included patent files from China. In the CNIPA and Derwent Innovation databases, 335 patent files were identified, of which two patents were irrelevant (nonpharmaceutical: Yang Zhi Gan Lu drink) and thus were excluded. In addition, 46 duplicate application numbers were excluded to avoid multiple inclusions of the same patent.

Ultimately, 287 patents with patent publication numbers were included in the analysis (Figure 1 and Table S1). We listed the 10 CCFs with the highest number of patents, of which the largest number was 13. CCFs with more than 10 patents were Banxiaxiexin decoction, Lingguizhugan decoction, Mahuang decoction, Qingfei decoction, and Yangwei decoction (Table 1), which did not contain ingredients from animals. The primary effects of these traditional formulas were focused on clearing heat and detoxification and seldom employed animal medicine.

Table 1

Top CCF by the number of patents

\begin{tabular}{|lll|}
\hline Rank & CCF & The Number of Patents \\
\hline 1 & Banxiaxiexin decoction & 13 \\
\hline 2 & Lingguizhugan decoction & 12 \\
\hline 3 & Mahuang decoction & 11 \\
\hline 5 & Qingfei decoction & 10 \\
\hline 6 & Yangwei decoction & 10 \\
\hline 7 & Jichuan decoction & 9 \\
\hline 8 & Dajianzhong decoction & 8 \\
\hline 9 & Wendan decoction & 8 \\
\hline 10 & Fuzi decoction & 8 \\
\hline
\end{tabular}

\section{Regions of inventors}

The addresses of inventors were predominantly located in economically developed coastal regions, such as the Yangtze River Delta (26\%), the Pearl River Delta (11\%), and Beijing-Tianjin-Hebei (10\%), as well as in the western region of China, Chengdu (6\%). Tsumura \& Co Ltd., a pharmaceutical company in Japan, was the only overseas inventors (Figure 2). Tsumura \& Co Ltd., which is one of the most successful companies globally in the development of traditional formulas, considers China as a viable market for traditional prescriptions.

\section{Patent inventors}


Among the top $10 \mathrm{CCF}$ inventors, six were from companies, three were from universities/hospitals, and only one was an individual (Table 2). The company with the most CCF patents was Suzhou Zhiweitang Bio-Tech Co, which applied for 34 different patents for protection between 2009 and 2011, including novel dosage forms and preparation methods of CCFs, such as Houpumahuang decoction, Baihedihuang decoction, and Gancaofuzi decoction. The Hebei University of Chinese Medicine was the academic institution with the most applications, which were largely for rapid thin-layer identification analytical methods; these were in granted status. Academic institutions, which are the backbones of CCF growth, had a deeper pool of patented technology than did businesses.

Table 2

Top 10 CCF assignees/inventors

\begin{tabular}{|lll|}
\hline Rank & Inventor & The number of patents \\
\hline 1 & Suzhou Zhiweitang Bio-Tech Co & 34 \\
\hline 2 & Hebei University Of Chinese Medicine & 8 \\
\hline 4 & China Resources Sanjiu Medical \& Pharmaceutical Co Ltd & 8 \\
\hline 5 & Hunan Xinhui Pharmacy Co Ltd & 7 \\
\hline 6 & Chengdu University Of Tcm & 5 \\
\hline 7 & Dong-e e-Jiao Co Ltd & 4 \\
\hline 8 & Guangzhou Zhidao Jingfang Technology Co Ltd & 4 \\
\hline 9 & Huang Daju & 4 \\
\hline 10 & Nanjing University Of Chinese Medicine & 4 \\
\hline
\end{tabular}

\section{Patent application trends}

We categorized all inventors into three groups to identify the themes that caused a change in the number of CCF applications. We used changes in the trend of number of applications to characterize how 'hot' the CCF was. The first CCF patent application, CN1232268, submitted in 2002 by Beijing University of Traditional Chinese Medicine was focused on a new spleen-strengthening indication, which has now expired (Figure 3). No CCF patents appeared in 2003; however, the number of patent applications showed a general upward trend from 2004. Before 2007, there were no companies among the inventors, although companies' share of patents increased annually from 2008 to 2011. From 2012, the number of patent applications fell abruptly; however, it increased gradually to reach a new peak of applications in 2019.

\section{IPC code characteristics}

The IPC codes of patents indicate the field of technology to which the invention relates. In this study, we counted the word frequencies of seven-digit IPC codes to identify the main directions covered by CCF patents. First, a total of 191 patents were marked with the code A61K036, which described pharmaceutical preparations containing undefined structures derived from algae, mosses, fungi, or plants or their derivatives, such as traditional herbs. Second, 93 patents were marked with the code G01N030, which described the use of adsorption, absorption, other similar phenomena, or ion exchange, for example, chromatography, which separates materials into components to test or analyze each material. Third, 89 patents were labeled A61K009, which described pharmaceutical preparations characterized by a particular physical shape. Fourth, 81 patents were marked with the code A61P001, which described drugs for the treatment of diseases of the digestive tract or digestive system. More than half $(67 \%)$ of CCF patents were focused on formulation research aimed at developing pharmaceutical formulations of acceptable bioavailability.

\section{Technological characteristics}

To more clearly and purposefully depict changes in the development of CCF technologies, the number of patented technology classifications in the seven categories was expressed in a line graph (Figure 5). The focus of patent technology categorization shifted from novel dosage forms to analytical methods in 2019. Quality control methods first appeared in 2016 (CN103237899), and patents for equipment appeared in 2018 (CN207666882). Preparation methods and new indications had a generally stable growth pattern, with quality control methods first appearing in 2016 and patents for related devices in 2017.

Four types of technologies accounted for a relatively high proportion of all patent documents (Figure 4): analytical methods (24.57\%), new indications $(22.84 \%)$, novel dosage forms $(22.15 \%)$ and preparation methods $(20.07 \%)$. Three other techniques, modified formulations (6.23\%), quality control methods (2.77\%), and equipment (0.69\%). Drug repositioning, which involves adding additional indications to current

Page $4 / 17$ 
clinical medications, constituted a reasonably high proportion of patents, indicating its popularity as an area of Research and Development (R\&D) and a new option for CCF R\&D; the advantages were minimal cost and time compared with new drug discovery.

\section{Granted patents of CCFs}

The number of patents currently available for different CCFs is listed in Table 3. At present, there are 162 granted patents, among which the longest granted patent is CN100515452, which was submitted in 2005 for 4361 days of protection. The three CCFs with the largest number of granted patents are Lingguizhugan decoction $(n=9)$, Zexie decoction $(n=8)$, and Dajianzhong decoction $(n=7)$. Of the Lingguizhushu decoction patents, four were for preparation methods, two for quality control methods, two for analytical methods, and one for equipment (Table 3). Granted included 69 analytical methods (42.59\%), 39 preparation methods (24.07\%), 25 new indications (15.43\%), 20 novel dosage forms (12.35\%), 6 quality control methods (3.70\%), 2 modified formulations (1.23\%), and 1 equipment (0.62\%; Figure 5). Analytical methods have the potential for commercial application and are currently the dominant type of technology for which patents are filed. 


\begin{tabular}{|c|c|c|c|c|c|c|c|c|c|}
\hline & & Alive pat & & & & & & & \\
\hline No. & $\begin{array}{l}\text { Chinese Classical } \\
\text { Formulas }\end{array}$ & $\begin{array}{l}\text { Number } \\
\text { of Alive }\end{array}$ & $\begin{array}{l}\text { New } \\
\text { indications }\end{array}$ & $\begin{array}{l}\text { New } \\
\text { dosage } \\
\text { forms }\end{array}$ & $\begin{array}{l}\text { Preparation } \\
\text { methods }\end{array}$ & Improvements & $\begin{array}{l}\text { Quality } \\
\text { control } \\
\text { methods }\end{array}$ & Equipment & $\begin{array}{l}\text { Analytical } \\
\text { methods }\end{array}$ \\
\hline 1 & $\begin{array}{l}\text { Banxiaxiexin } \\
\text { decoction }\end{array}$ & 6 & 1 & 2 & 3 & 0 & 0 & 0 & 0 \\
\hline 2 & $\begin{array}{l}\text { Lingguizhugan } \\
\text { decoction }\end{array}$ & 9 & 0 & 0 & 4 & 0 & 2 & 1 & 2 \\
\hline 3 & Mahuang decoction & 4 & 0 & 2 & 2 & 0 & 0 & 0 & 0 \\
\hline 4 & Qingfei decoction & 2 & 1 & 0 & 0 & 0 & 0 & 0 & 1 \\
\hline 5 & Yangwei decoction & 5 & 3 & 0 & 0 & 0 & 0 & 0 & 2 \\
\hline 6 & Jichuan decoction & 5 & 1 & 0 & 1 & 0 & 2 & 0 & 1 \\
\hline 7 & Zexie decoction & 8 & 4 & 0 & 0 & 0 & 0 & 0 & 4 \\
\hline 8 & $\begin{array}{l}\text { Dajianzhong } \\
\text { decoction }\end{array}$ & 7 & 0 & 2 & 2 & 0 & 0 & 0 & 3 \\
\hline 9 & Wendan decoction & 5 & 1 & 2 & 2 & 0 & 0 & 0 & 0 \\
\hline 10 & Fuzi decoction & 1 & 0 & 0 & 1 & 0 & 0 & 0 & 0 \\
\hline 11 & $\begin{array}{l}\text { Baihedihuang } \\
\text { decoction }\end{array}$ & 5 & 0 & 1 & 2 & 0 & 0 & 0 & 2 \\
\hline 12 & Huagai san & 5 & 1 & 0 & 1 & 0 & 0 & 0 & 3 \\
\hline 13 & $\begin{array}{l}\text { Taohongsiwu } \\
\text { decoction }\end{array}$ & 4 & 0 & 1 & 0 & 1 & 0 & 0 & 2 \\
\hline 14 & $\begin{array}{l}\text { Dangguisini } \\
\text { decoction }\end{array}$ & 5 & 3 & 0 & 0 & 0 & 1 & 0 & 1 \\
\hline 15 & Dayuan decoction & 2 & 1 & 0 & 1 & 0 & 0 & 0 & 0 \\
\hline 16 & $\begin{array}{l}\text { Wuweixiaodu } \\
\text { decoction }\end{array}$ & 4 & 0 & 2 & 1 & 0 & 0 & 0 & 1 \\
\hline 17 & $\begin{array}{l}\text { Taohechengqi } \\
\text { decoction }\end{array}$ & 4 & 0 & 0 & 1 & 0 & 1 & 0 & 2 \\
\hline 18 & $\begin{array}{l}\text { Dangguibuxue } \\
\text { decoction }\end{array}$ & 1 & 0 & 0 & 0 & 0 & 0 & 0 & 1 \\
\hline 19 & Baoyuan decoction & 5 & 0 & 0 & 0 & 0 & 0 & 0 & 5 \\
\hline 20 & $\begin{array}{l}\text { Huangqiguizhiwuwu } \\
\text { decoction }\end{array}$ & 4 & 1 & 0 & 2 & 0 & 0 & 0 & 1 \\
\hline 21 & Xiebai san & 4 & 0 & 0 & 0 & 0 & 0 & 0 & 4 \\
\hline 22 & Yiwei decoction & 1 & 1 & 0 & 0 & 0 & 0 & 0 & 0 \\
\hline 23 & $\begin{array}{l}\text { Maimendong } \\
\text { decoction }\end{array}$ & 0 & 0 & 0 & 0 & 0 & 0 & 0 & 0 \\
\hline 24 & Zhenwu decoction & 2 & 1 & 1 & 0 & 0 & 0 & 0 & 0 \\
\hline 25 & $\begin{array}{l}\text { Shashenmaidong } \\
\text { decoction }\end{array}$ & 2 & 0 & 0 & 1 & 0 & 0 & 0 & 1 \\
\hline 26 & Zhuling decoction & 1 & 0 & 0 & 0 & 0 & 0 & 0 & 1 \\
\hline 27 & $\begin{array}{l}\text { Xiaochengqi } \\
\text { decoction }\end{array}$ & 1 & 0 & 0 & 1 & 0 & 0 & 0 & 0 \\
\hline 28 & $\begin{array}{l}\text { Zhishixiebaiguizhi } \\
\text { decoction }\end{array}$ & 1 & 0 & 0 & 1 & 0 & 0 & 0 & 0 \\
\hline
\end{tabular}




\begin{tabular}{|c|c|c|c|c|c|c|c|c|c|}
\hline & & & & & & & & & \\
\hline 29 & Guihua san & 1 & 0 & 0 & 1 & 0 & 0 & 0 & 0 \\
\hline 30 & $\begin{array}{l}\text { Dangguiliuhuang } \\
\text { decoction }\end{array}$ & 4 & 0 & 0 & 1 & 0 & 0 & 0 & 3 \\
\hline 31 & Yiguan decoction & 1 & 0 & 0 & 0 & 0 & 0 & 0 & 1 \\
\hline 32 & Ganlu decoction & 3 & 0 & 0 & 2 & 0 & 0 & 0 & 1 \\
\hline 33 & $\begin{array}{l}\text { Gancaoxiexin } \\
\text { decoction }\end{array}$ & 2 & 0 & 1 & 1 & 0 & 0 & 0 & 0 \\
\hline 34 & $\begin{array}{l}\text { Banxiahoupu } \\
\text { decoction }\end{array}$ & 1 & 0 & 0 & 1 & 0 & 0 & 0 & 0 \\
\hline 35 & $\begin{array}{l}\text { Houpuqiwu } \\
\text { decoction }\end{array}$ & 2 & 0 & 1 & 0 & 0 & 0 & 0 & 1 \\
\hline 36 & Sanhua decoction & 3 & 0 & 0 & 2 & 0 & 0 & 0 & 1 \\
\hline 37 & Huanglian paste & 0 & 0 & 0 & 0 & 0 & 0 & 0 & 0 \\
\hline 38 & $\begin{array}{l}\text { Xuanfudaizhe } \\
\text { decoction }\end{array}$ & 2 & 1 & 1 & 0 & 0 & 0 & 0 & 0 \\
\hline 39 & Wuzhuyu decoction & 0 & 0 & 0 & 0 & 0 & 0 & 0 & 0 \\
\hline 40 & $\begin{array}{l}\text { Shaoyaogancao } \\
\text { decoction }\end{array}$ & 2 & 0 & 1 & 0 & 0 & 0 & 0 & 1 \\
\hline 41 & Huanglian decoction & 0 & 0 & 0 & 0 & 0 & 0 & 0 & 0 \\
\hline 42 & $\begin{array}{l}\text { Guizhishaoyaozhimu } \\
\text { decoction }\end{array}$ & 3 & 0 & 0 & 0 & 0 & 0 & 0 & 3 \\
\hline 43 & Huagan decoction & 3 & 0 & 0 & 1 & 0 & 0 & 0 & 2 \\
\hline 44 & Erdong decoction & 3 & 0 & 0 & 0 & 0 & 0 & 0 & 3 \\
\hline 45 & $\begin{array}{l}\text { Simiaoyongan } \\
\text { decoction }\end{array}$ & 0 & 0 & 0 & 0 & 0 & 0 & 0 & 0 \\
\hline 46 & Sanpian decoction & 2 & 0 & 0 & 1 & 0 & 0 & 0 & 1 \\
\hline 47 & $\begin{array}{l}\text { Ganjianglingshu } \\
\text { decoction }\end{array}$ & 2 & 0 & 0 & 0 & 0 & 0 & 0 & 2 \\
\hline 48 & Yunv decoction & 1 & 0 & 0 & 0 & 0 & 0 & 0 & 1 \\
\hline 49 & $\begin{array}{l}\text { Dangguijianzhong } \\
\text { decoction }\end{array}$ & 1 & 0 & 0 & 0 & 0 & 0 & 0 & 1 \\
\hline 50 & Dihuang decoction & 2 & 0 & 1 & 0 & 1 & 0 & 0 & 0 \\
\hline 51 & $\begin{array}{l}\text { Zhuyeshigao } \\
\text { decoction }\end{array}$ & 1 & 0 & 0 & 1 & 0 & 0 & 0 & 0 \\
\hline 52 & $\begin{array}{l}\text { Gualouxiebaibanxia } \\
\text { decoction }\end{array}$ & 2 & 1 & 1 & 0 & 0 & 0 & 0 & 0 \\
\hline 53 & $\begin{array}{l}\text { Xiaoxuanming } \\
\text { decoction }\end{array}$ & 2 & 1 & 0 & 1 & 0 & 0 & 0 & 0 \\
\hline 54 & Wenjing decoction & 1 & 0 & 0 & 0 & 0 & 0 & 0 & 1 \\
\hline 55 & $\begin{array}{l}\text { Qingxinlianzi } \\
\text { decoction }\end{array}$ & 1 & 0 & 1 & 0 & 0 & 0 & 0 & 0 \\
\hline 56 & $\begin{array}{l}\text { Jinshuiliujun } \\
\text { decoction }\end{array}$ & 2 & 0 & 0 & 0 & 0 & 0 & 0 & 2 \\
\hline 57 & Liangdi decoction & 2 & 0 & 0 & 0 & 0 & 0 & 0 & 2 \\
\hline 58 & Wenpi decoction & 0 & 0 & 0 & 0 & 0 & 0 & 0 & 0 \\
\hline
\end{tabular}




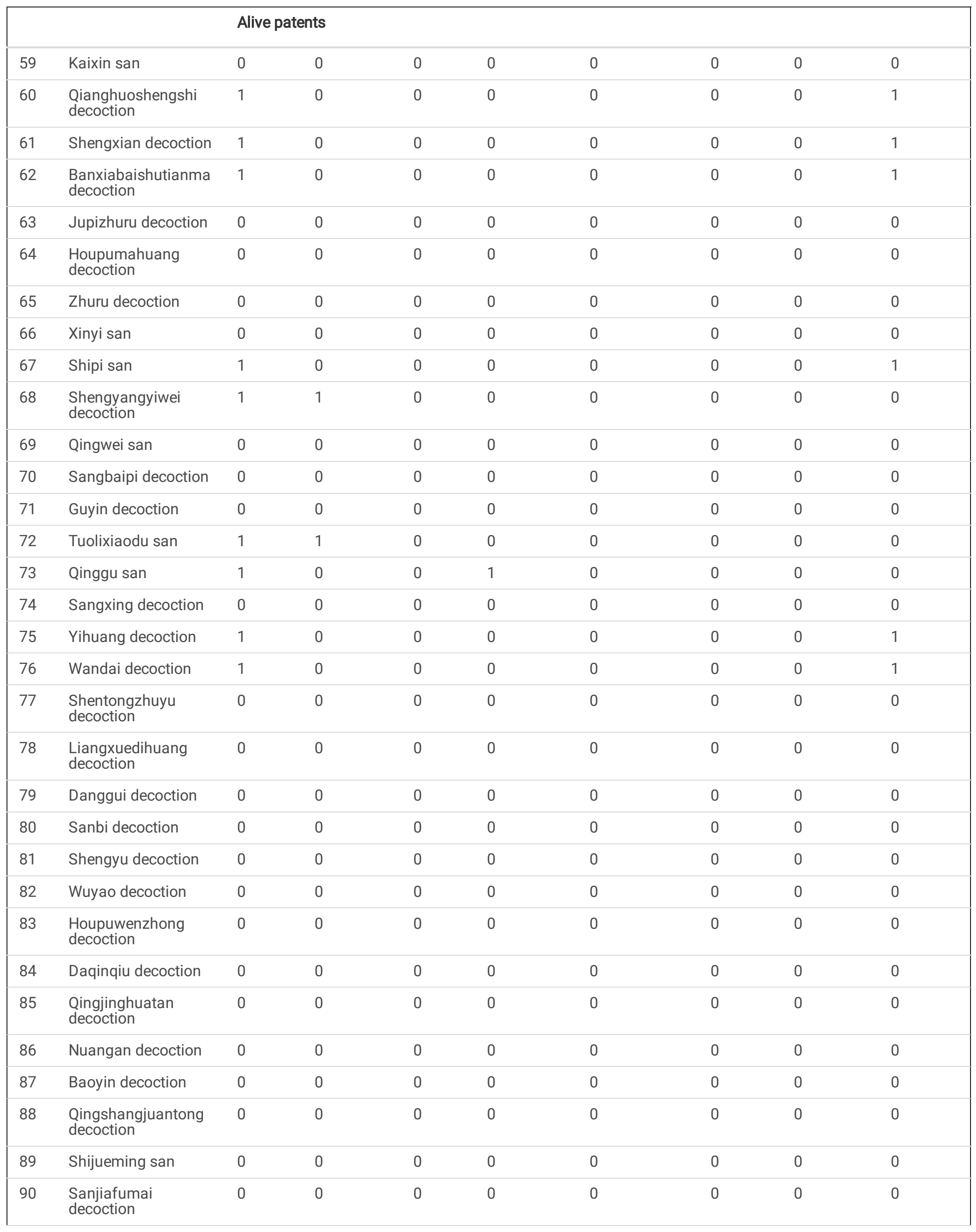




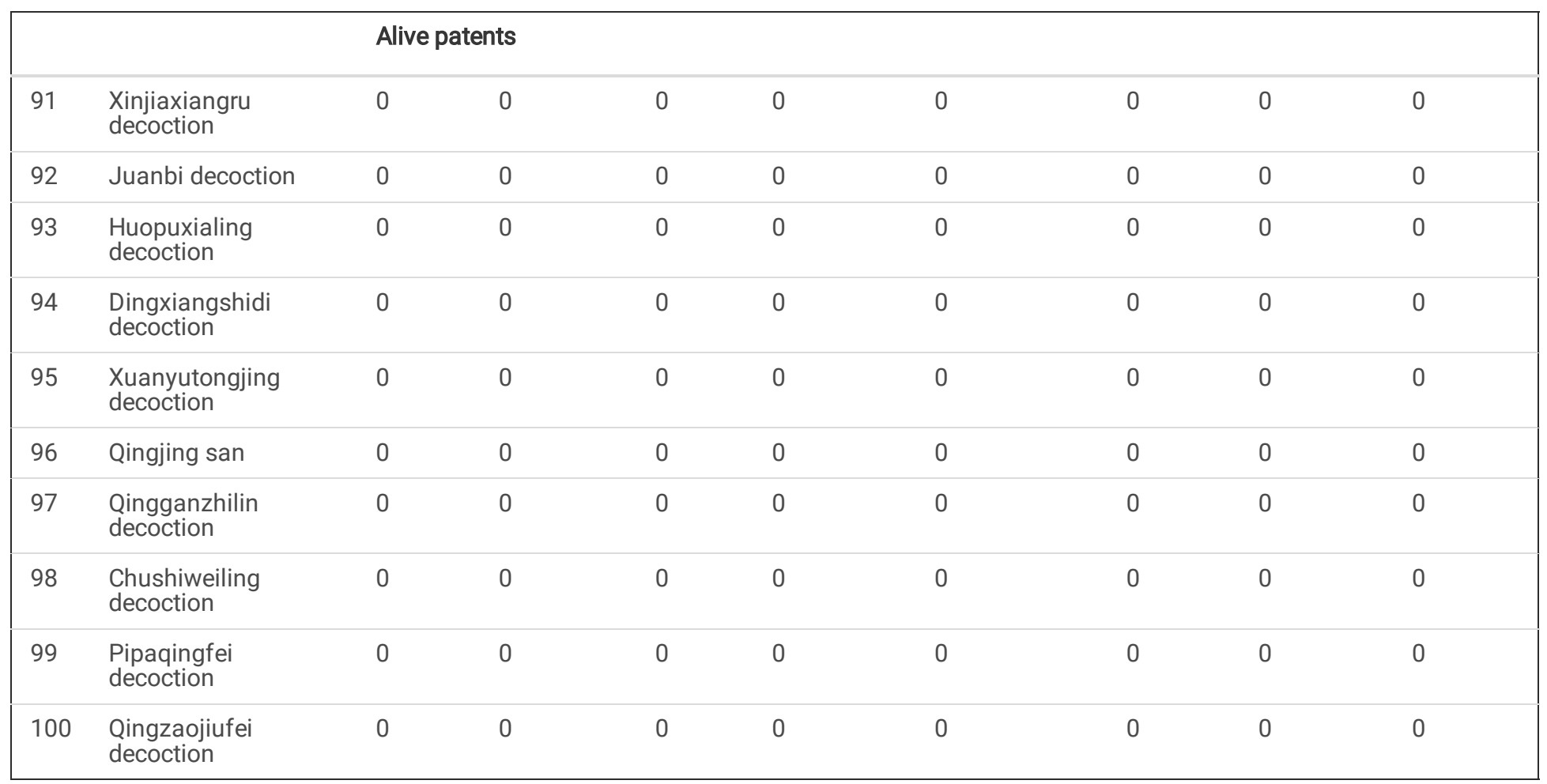

\section{Box 1. Key Messages On Tsumura Case}

Temporal. With Japan Kampo medicines rapid development in the past 50 years [11-13]. Tsumura \& Co Ltd. since 1936, and was listed on the Tokyo Stock Exchange on January 5, 1984. In 2020, Tsumura \& Co Ltd. accounted for over $80.0 \%$ of the market share for Kampo medicines, Kampo medicines account for $95.2 \%$ of the main business.

Policies. In 1976, Japan's Ministry of Health, Labour and Welfare has established a medical insurance system for Kampo medicines, approved the use of 210 ancient prescriptions [14, 15]. Japan Kampa Medicines Manufacturers Association (JKMA) was established on July 21, 1983 by domestic manufacturers and distributors (including importers) of Kampa products and crude drug products derived from crude drug, as well as other businesses associated with raw materials for crude drug. [16].

Enlightenment. The average implementation rate of Japanese patented technologies is $52 \%$, which is much higher than the world average [17-19]. By evaluating Tsumura \& Co Ltd.'s patent development trajectory and granted patents, we provide inspiration and references for CCF's R\&D.

\section{Traditional formulas development enterprise: Tsumura \& Co Ltd.}

We searched "Tsumura \& Co Ltd." in the Derwent Innovation Database and ended up with 1,446 patents up to 15 August 2021 (Figure S1). Tsumura \& Co Ltd. received its first patent in 1972, and the number of patents began to rapid growth in 1987, peaking in 1992 ( $\mathrm{n}=123$ ), before drastically declining in 1996. From 1999 to 2021, Tsumura \& Co Ltd. has a growth of 10-35 new patents each year (Figure S2). Tsumura \& Co Ltd. began marketing Kampo medicines in 1974, 33 Kampo medicines were included in Medicare in 1976, Tsumura \& Co Ltd. were listed on the Tokyo Stock Exchange in 1982 and Side effects of interstitial pneumonia caused by Xiaochaihu decoction in 1995. Corporate revenue experienced a period of decline from 1991 to 1998, and overall growth was maintained in 1972 to 2019 [10] (Figure S2).

Tsumura \& Co Ltd. has public patents in 28 different countries/regions, including JP ( $n=940,65.01 \%)$, WO ( $n=88,6.09 \%)$, US ( $n=82,5.67 \%)$, EP $(n=69,4.77 \%)$, and CN $(n=52,3.60 \%)$. CN began publication a substantial number of patents in 2004 and has continued to do so in several years. The patent application was filed in numerous Asian countries/regions (Figure S3). Of the publication patents by Tsumura \& Co Ltd., combinations ( $n=702,48.55 \%)$, new compounds ( $n=349,24.14 \%)$, production methods and equipment ( $n=324,22.41 \%)$, analysis methods( $n=71,4.91 \%)$. new compounds were found and employed primarily from 1988 to 1998, while production methods and equipment were published practically every year from 1980 to 2007. After 2007, a slew of analysis methods publishes (Figure S4).

Tsumura \& Co Ltd.'s granted patents. Currently Tsumura \& Co Ltd. has 189 granted patents, including JP ( $n=60,31.75 \%), C N$ ( $n=34,17.99 \%)$, US ( $n=22,11.64 \%)$, TW ( $n=20,10.58 \%)$, HK ( $n=16,8.47 \%)$; production methods and equipment $(n=103,54.50 \%)$, analysis methods ( $n=51$, $26.98 \%)$, combinations ( $n=23,12.17 \%)$, new compounds $(n=12,6.35 \%)$. 
List of core patents from citations, Multi-Component Medicine Evaluation Method (W02005121777A1), it is possible to provide a method for evaluating the quality, safety, efficiency, and the like of the multi-component medicine to be evaluated, by a single numeric value using the Mahalanobis distance. Panax ginseng C.A.Mey. Cultivation Method (WO2012046601A1), disclosed is an efficient cultivation method of Panax ginseng C.A.Mey. which prevents damage from continuous cropping particular to Panax ginseng C.A.Mey., and is capable of reducing the work involved in cultivation.Microbial Cell Culture Medium, And Microbial Cell Culture Method (W02008038625A1), disclosed is a microbial cell culture medium which can certainly proliferate a target bacterial cell contained in a sample having an antibacterial activity. Also disclosed is a method for culture of a microbial cell. Specifically disclosed is a microbial cell culture medium for proliferating a target bacterial cell contained in a sample having an antibacterial activity. Also specifically disclosed is a microbial cell culture method for proliferating a target bacterial cell contained in a sample having an antibacterial activity, in a microbial cell culture medium.

\section{Discussion Policy effects}

After a patent application is completed, the waiting time until disclosure is the most time-consuming period before a patent is granted [20]. On average, each patent required at least 800 days to be disclosed before 2006 and at least 1 year to be disclosed from 2006 to 2018 . At the end of 2018, China's State Council issued a document on 'strengthening the protection of intellectual property rights of ancient Chinese classical prescriptions,' which resulted in a cliff-like decline in disclosure times from 2019, with the average time for each patent to be disclosed after 2019 reducing to less than 200 days. This policy greatly shortened the disclosure time of CCF patents.

The policy release coinciding with the rapid increase in the number of patents and short time of patent publication indicates a positive impact of policies on the development of CCFs [21]. However, it is worth noting that although the number of patent applications increased rapidly in 2011 and 2019, the number of applications dropped sharply in the year following these growth points and returned to normal growth levels in the following year. The main inventors in the first phase were businesses, and applications were predominantly for new dosage forms that were simple to develop. Because the policy clarified the norms and directives, selection of dosage forms with reference to ancient sources Moreover, although applicants were mostly corporations in the second fluctuation, the number of patents for new dosage forms fell dramatically, and the focus of patents shifted to analytical methods. This shift in application direction demonstrated that the majority of CCF developers were not self-employed and relied on governmental guidelines for their R\&D.

Companies are the primary drivers of the rapid growth and decline in the number of patent applications, which indicates that companies are the most sensitive to policy and that such sensitivity, although beneficial, may necessitate timely introductions of other CCF-related policies to ensure the continued development of technologies. In general, Chinese CCF developers are highly concerned about the policies introduced and are moving towards deeper technical depth.

\section{Commercialization}

Although China government encourages the development of CCFs by introducing policies, the level of capital recognition is an important component [22]. We evaluated and predicted the commercialization of CCF development by the trend of change in inventor type and revealed that during the first 6 years of CCF patent applications, inventors were mainly individuals and universities/hospitals, whereas the first company-type inventors (Beijing Jinfanghua Pharmaceutical Technology Co Ltd, CN101264276/CN101229306/CN101284051,

Dayuan/Guyin/Jichuan decoctions) began appearing from 2008 until 2021, with companies filing patents each year. Company-type inventors dominated the fluctuations in application numbers twice. The main goal of companies is profitability, and the share of companies among all inventors has increased in recent years, which indicates that capital is starting to pay attention to the development of CCFs and recognizing the market for CCF.

The mainstream technology of patents ranges from the development of new dosage forms to the development of analytical methods. The reasons for this change may stem from two official actions. In 2011, the director of the State Administration of Traditional Chinese Medicine of China visited Hong Kong to attend an international conference on classical prescriptions and clinical indications. In 2019, a public call was made for comments on the CCFPP and its material reference information. During the early period, most patents were owned by individuals; however, the dominance of individual patents was gradually replaced by companies and universities/hospitals during the later stage. In recent years, universities and research centers have played increasingly more important roles in CCF development compared with companies. These changes reflect the trend of commercialization of CCF-related inventions (Figure 3).

Inventors' priority country or region (i.e., where the inventors protect their patents) could be determined from our data. In general, patent inventors applied for patent rights only in countries or regions where there was a potential market for the product [21]. Furthermore, not only Chinese enterprises filed patents in China; for example, Tsumura \& Co Ltd. of Japan filed patents in China, which demonstrates the continued 
internationalization and appeal of the Chinese market [23, 24]. Overall, capital entry is a positive sign for developers and governments [25], while companies offer dynamism to the development of CCF technology [26]. However, there may also be a boilerplate patent bubble that will eventually not adopted/invalidated these patents.

\section{Recommendation on CCF R\&D}

To demonstrate the historical route of CCF R\&D, we discuss some milestone patents: 1) Marking the beginning of CCF intellectual property, the first CCF patent CN1232268 was invented by Beijing University of Traditional Chinese Medicine in 2002 and granted on June 13, 2012. 2) The only overseas inventor, the patent of Tsumura \& Co Ltd.. (CN103237899) was filed in 2011 and disclosed in 2016, which was related to the bioassay and pharmacological evaluation methods of the Dajianzhong decoction in RIN-14B cell cultures. Subsequently, CN108779484, filed in 2017 and disclosed in 2018, was used to predict the administration dosage of Dajianzhong decoction based on the class phylum to thick-walled phylum ratio of patients' intestinal tracts. These two inventions have since been submitted for protection in seven countries/regions, including Japan, the United States, and the European Union. 3) The longest granted time was for the patent CN100515452, which was filed by Huang Daju in 2005 and disclosed in 2009. It was marketed as an oral preparation of the Wuweizi decoction, which was developed using modern technology, and has the longest validity and largest commercial value of all granted patents. 4) The patent with the highest citation rate is a patent that is primarily cited by subsequent patents; it represents the most basic and innovative technology with high inventiveness and is what others in the field try to imitate. CN102895432 was filed by Wang Dengzhi in 2011 and is a new dosage form of 'happy pills' for the prevention or treatment of Alzheimer's disease. It was most frequently cited (29 times in total) for inventions of Alzheimer's disease treatments and the preparation of granules. In general, compared with patents of overseas units, patents of Chinese inventors were invalidated because of a lack of commercial value [10,11], which has continued to be a common problem for current patent applications.

We have provided an overview of the development of CCF patents in the previous sections and overview contributes to CCF development. Each CCF has attracted different levels of attention, and among the 100 CCFs, 39 CCFs had no granted patents, and 82 CCFs had $\leq 4$ granted patents. With the entry of corporate capital, CCF is an area to be recognized and will soon enter the 'fast track' period [25]. In addition, CCFs may require the introduction of further relevant policies to ensure a high level of attention [27]. Despite financial and legislative backing, the majority of CCFs are now method patents with low invention complexity and weak barging power and constitutes only a few key patents. The development of CCFs will need to overcome this issue in the future as it expands internationally [28].

\section{Insights from Tsumura Case.}

The R\&D of Tsumura \& Co Ltd., a leading global developer of traditional prescriptions, analysis of their technological status and development, aid in the further development of CCFs. In 1976, the Japanese government included Kampo medicines in the medical insurance scheme, which gave impetus to the secondary development of traditional prescriptions in Japan, and in the same way as the CCF, policy was the first driving force behind the development of the industry. In 1983, the JKMA was established, contributing to the cooperation and supervision of the Japanese traditional medicine industry and supporting the development of high quality traditional medicines in Japan. During Tsumura \& Co Ltd.'s period of rapid development (1976-1987), 129 preparations of Kampo medicines were applied for manufacture and sell them were obtained.At the same time, with patents being filed for combinations and new compounds, but most of these patents are ungranted, and now granted patent on production methods and equipment and analysis methods.

In addition, compared to CCF's patents and Tsumura \& Co Ltd.'s patents, Tsumura \& Co Ltd. often use modern medical terms in the patent text to describe the diseases treated, and the diseases involved are mainly focused on diabetes complications, kidney diseases, cancer and tumour. And the patents are all medicine pairs, so making the patents more adaptable and protective, Tsumura \& Co Ltd.'s patents type covers the upstream of the production of the product and is applied for in collaboration with several companies, including cultivation methods, production equipment, production methods and evaluation methods. There are two main points of similarity between the CCF and Tsumura \& Co Ltd., They have the same degree of internationalisation, and analysis methods are the same hotspot in recent years. The development and establishment of related cultivation methods, production methods and evaluation methods for CCF can help to improve the integrity of the industry, increase the voice of CCF developers in the industry and further enhance the competitiveness of developers.

Predicting possible future problems from the past experience of Tsumura \& Co Ltd. 1) Focus on drug safety to avoid drug abuse. In 1995 the prolonged use of Xiaochaihu decoction by Japanese hepatitis patients caused organic pneumonia [29-31], causing the Japanese public to reduce faith about Kampo medicines. 2) Reduce the inconsistencies in raw material crude drugs. Tsumura \& Co Ltd. sources $80 \%$ of its production materials from China and 15\% from Japan, in addition to a Good Agricultural and Collection Practice (GAMP) with a traceability system, a complete transport and storage system [10]. 3) Focus on R\&D investment. In 2019, R\&D Expenses Margin reached 5.0\%, the highest percentage of R\&D investment by any Chinese and Japanese Herb medicine company, and the high percentage of R\&D investment has helped it to shift its R\&D direction and maintain its operations after the Xiaochaihu decoction incident. 4)Scientific analysis of traditional 
formulas using new technologies. Tsumura \& Co Ltd. has been concentrating its resources on the establishment of scientific evidence for its Kampo formulations in its research activities, it will be necessary for these formulations to be understood through the framework of Western medicine [10].

There remain several research limitations to our analysis. Although patents are key innovation indicators, this patent-based analyses do not reflect all CCF R\&D efforts. But based on a large number of CCF reviews, we believe that patent analysis is necessary supplement to prior work. Furthermore, while the number of CCF patents is steadily increasing and the pace of R\&D is quickening, are there any inventions that are both innovative and marketable? If so, how many are there? Also, as a successful representative of the rehabilitation of conventional formulations, what is the patent situation in Japan, and what is their patent landscape? We believe it is important to keep an eye on these issues since it will help us stay focused on the development of traditional therapies.

\section{Conclusions}

Policy has a significant influence on CCF R\&D, and the popular trend is spreading annually. With companies as primary applicants, CCFs are beginning to be recognized to have considerable market potential, and the number of patent applications is increasing each year, which indicates that the rapid growth of CCF development will continue in the future. However, the lack of high-quality patents may pose future development difficulties, which will be an important issue to resolve.

\section{Abbreviations}

CCF: Chinese Classical Formulas;

CCFPP: CCF pharmaceutical preparations;

CNIPA: China National Intellectual Property Administration;

IPC: International Patent Classification;

IP\Intellectual Property

R\&D: Research and Development

JKMA: Japan Kampo Medicines Manufacturers Association

GAMP: Good Agricultural and Collection Practice

\section{Declarations}

\section{Acknowledgments}

We are grateful to the University of Macau Wu Yeesun Library for providing effective data service.

\section{Authors' contributions}

RP and YJ organized, conceived and supervised the study. YT collected the data. RP drafted the manuscript. HL and YZ provided input. HL, ZF and SW revised the manuscript. All authors have read and approved the final version of the manuscript.

\section{Funding}

This work was funded by the Macau Centre for Research and Development in Chinese Medicine (FDCT/007/2020/ALC) and the Research Fund of University of Macau (CPG2021-00022-ICMS).

\section{Availability of data and materials}

Not applicable.

\section{Ethics approval and consent to participate}

Not applicable.

\section{Consent for publication}


We declare that the Publisher has the Author's permission to publish the relevant contribution.

\section{Competing interests}

The authors declare that they have no competing interests.

\section{References}

1. Tu YJNm. The discovery of artemisinin (qinghaosu) and gifts from Chinese medicine. 2011; 17(10): 1217-1220.

2. Raffetin A, Bruneel F, Roussel C, et al. Use of artesunate in non-malarial indications. 2018; 48(4): $238-249$.

3. Fontanarosa PB, Lundberg GDJJ. Alternative medicine meets science. 1998; 280(18): 1618-1619.

4. Yuan R, Lin YJP, therapeutics. Traditional Chinese medicine: an approach to scientific proof and clinical validation. 2000; 86(2): 191198.

5. National Administation of Traditional Chinese Medicine. Circular of the National Administation of Traditional Chinese Medicine on Soliciting Opinions on the Selection Scope and Principles of the Catalogue of Ancient Classical Prescriptions. 2017; Available from: http://kjs.satcm.gov.cn/zhengcewenjian/2018-03-24/3520.html.

6. National Administation of Traditional Chinese Medicine. The Department of Science and Technology of the State Administration of Traditional Chinese Medicine held a symposium on the secondary development of CCF and the internationalization of Chinese medicine. 2010; Available from: http://kjs.satcm.gov.cn/gongzuodongtai/2018-03-24/3385.html.

7. National Administation of Traditional Chinese Medicine. Notice of the National Administation of Traditional Chinese Medicine on the Issuance of the "Catalog of Ancient Classical Prescriptions (First Batch)". 2018; Available from: http://kjs.satcm.gov.cn/zhengcewenjian/2018-04-16/7107.html.

8. Luo H, Chen H, Liu C, et al. The key issues and development strategy of Chinese Classical Formulas pharmaceutical preparations. $2021 ; 16(1): 1-14$.

9. Smith JA, Arshad Z, Trippe A, Collins GS, Brindley DA, Carr AJJNb. The reporting items for patent landscapes statement. 2018; 36(11): 1043-1047.

10. Ltd. TC. Integrated Report 2020. 2021; Available from: https://www.tsumura.co.jp/english/info/integrated_report.html.

11. Yu F, Takahashi T, Moriya J, et al. Traditional Chinese medicine and Kampo: a review from the distant past for the future. 2006; 34(3): 231-239.

12. Terasawa KJE-BC, Medicine A. Evidence-based reconstruction of Kampo medicine: part I-is Kampo CAM? 2004; 1(1): 11-16.

13. Maegawa H, Nakamura T, Saito KJJoe. Regulation of traditional herbal medicinal products in Japan. 2014; 158: 511-515.

14. Watanabe K, Matsuura K, Gao P, et al. Traditional Japanese Kampo medicine: clinical research between modernity and traditional medicine-the state of research and methodological suggestions for the future. $2011 ; 2011$.

15. Arai IJTC. The current situation of the Japanese medical plants industry and its significance for the pharmaceutical industry. 2009.

16. Association JKMM. JKMA Outline. 2021; Available from: https://www.nikkankyo.org/jkma_guide/english_guide/english2.htm.

17. Nagaoka S. Reform of patent system in Japan and challenges. in 21st Century Innovation Systems for Japan and the United States: Lessons from a Decade of Change: Report of a Symposium. 2009. National Academies Press.

18. Martinez C, Guellec D. Overview of recent changes and comparison of patent regimes in the United States, Japan and Europe. in Patents, Innovations and Economic Performance: OECD Conference Proceedings. 2004.

19. Masujima M, Tanaka YJIJoL, Enquiry S. Why Japan boasts of the most patent applications in the world. $2011 ; 4(3)$ : $185-201$.

20. Gerken JM, Moehrle MG, Walter LJR, Management D. One year ahead! Investigating the time lag between patent publication and market launch: insights from a longitudinal study in the automotive industry. 2015; 45(3): 287-303. 
21. Bessen J, Meurer MJJL, Rev. CL. Lessons for patent policy from empirical research on patent litigation. 2005 ; 9: 1.

22. Owens JJNRDD. Funding for accelerating drug development initiative critical. 2006; 5(4): $271-271$.

23. Lyu L, Feng Y, Chen X, Hu Y, The global chimeric antigen receptor T (CAR-T) cell therapy patent landscape. 2020, Nature Publishing Group.

24. Liu K, Zuo H, Li G, Yu H, Hu YJPr. Global research on artemisinin and its derivatives: Perspectives from patents. 2020; 159 : 105048.

25. Iwaisako T, Futagami KJET. Patent protection, capital accumulation, and economic growth. 2013; 52(2): 631-668.

26. Liu Q, Wong KPJMS. Intellectual capital and financing decisions: Evidence from the US patent data. 2011; 57(10): 1861-1878.

27. Gong H, Peng SJS. Effects of patent policy on innovation outputs and commercialization: evidence from universities in China. 2018; 117(2): 687-703.

28. Boeing P, Mueller EJEL. Measuring patent quality in cross-country comparison. 2016; 149: $145-147$.

29. Sato A, Toyoshima M, Kondo A, Ohta K, Sato H, Ohsumi AJTJjotd. Pneumonitis induced by the herbal medicine Sho-saiko-to in Japan. 1997; 35(4): 391-395.

30. Tojima H, Yamazaki T, Tokudome TJTJjotd. Two cases of pneumonia caused by Sho-saiko-to. 1996; 34(8): 904-910.

31. Tomioka H, Hashimoto K, Ohnishi H, et al. An autopsy case of interstitial pneumonia probably induced by Sho-saiko-to. 1999; 37(12): 1013-1018.

Figures

Searched

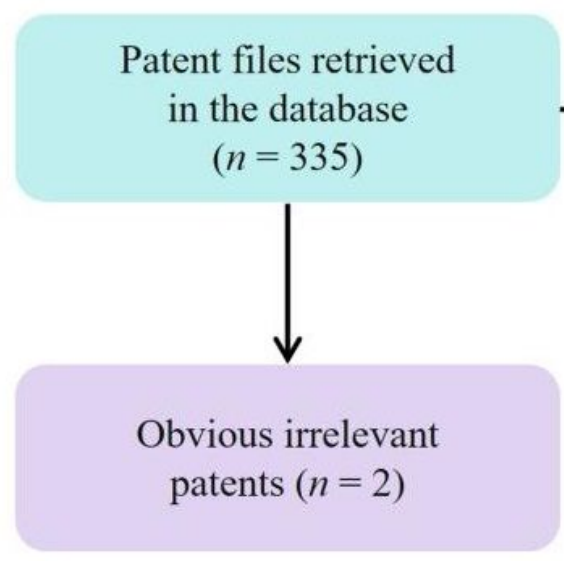

Refined

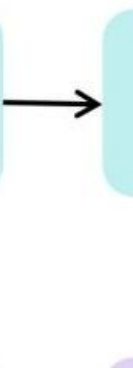
eligibility $(n=333)$
Patent files for

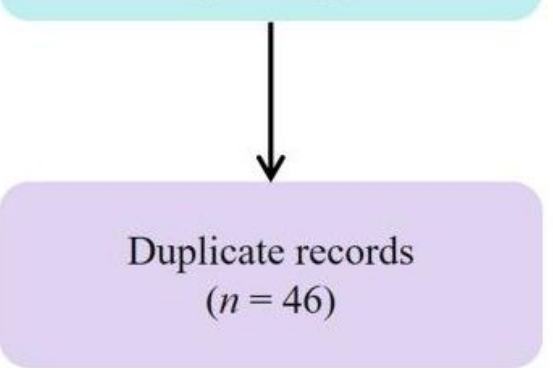

Included

Files included in patent analysis $(n=287)$

\section{Figure 1}

Flow diagram of patent sample. The purple boxes show the number of excluded patent files and the relevant reasons. 


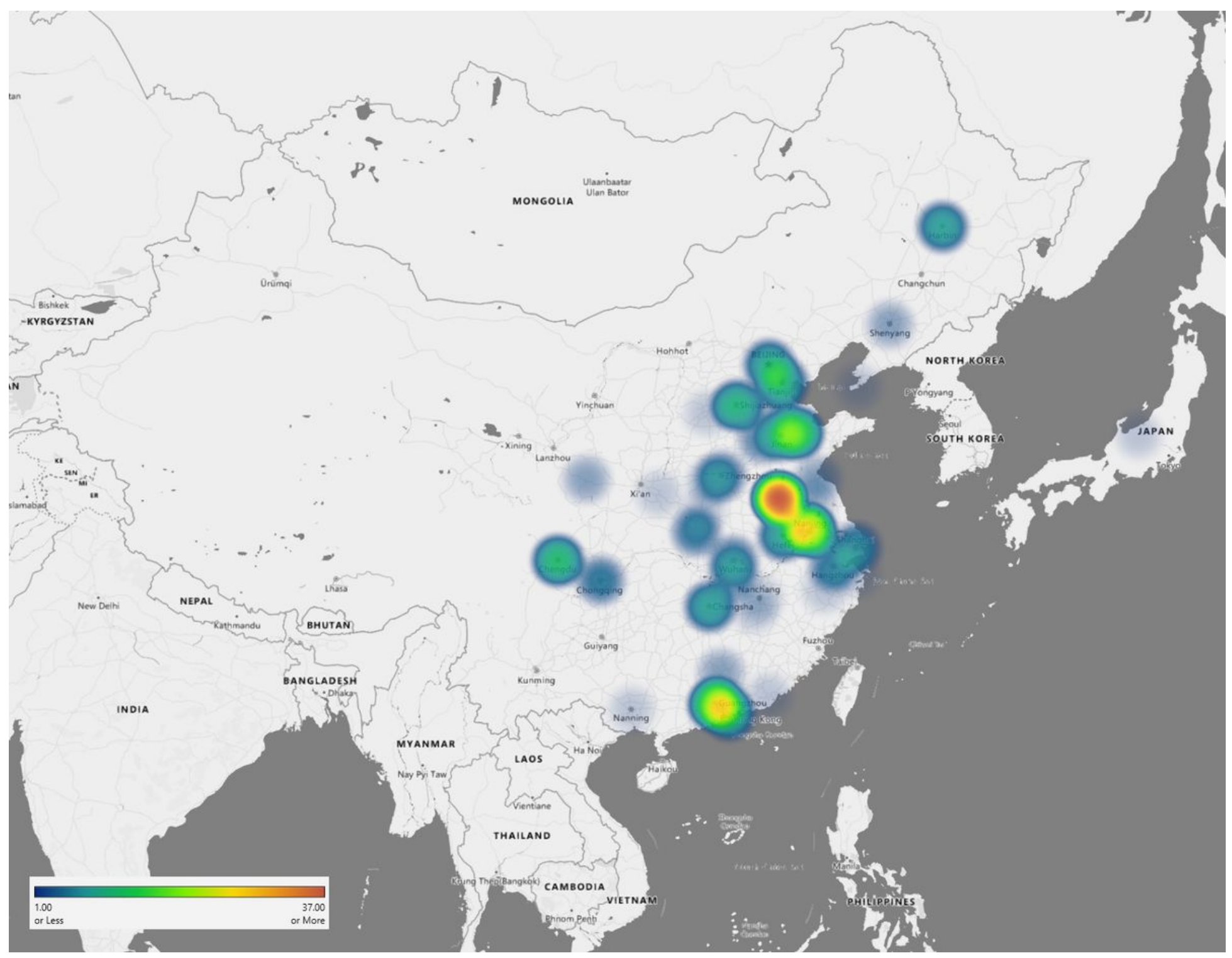

\section{Figure 2}

Heat map of inventor locations. The brighter color means the more patent applications in the area. 


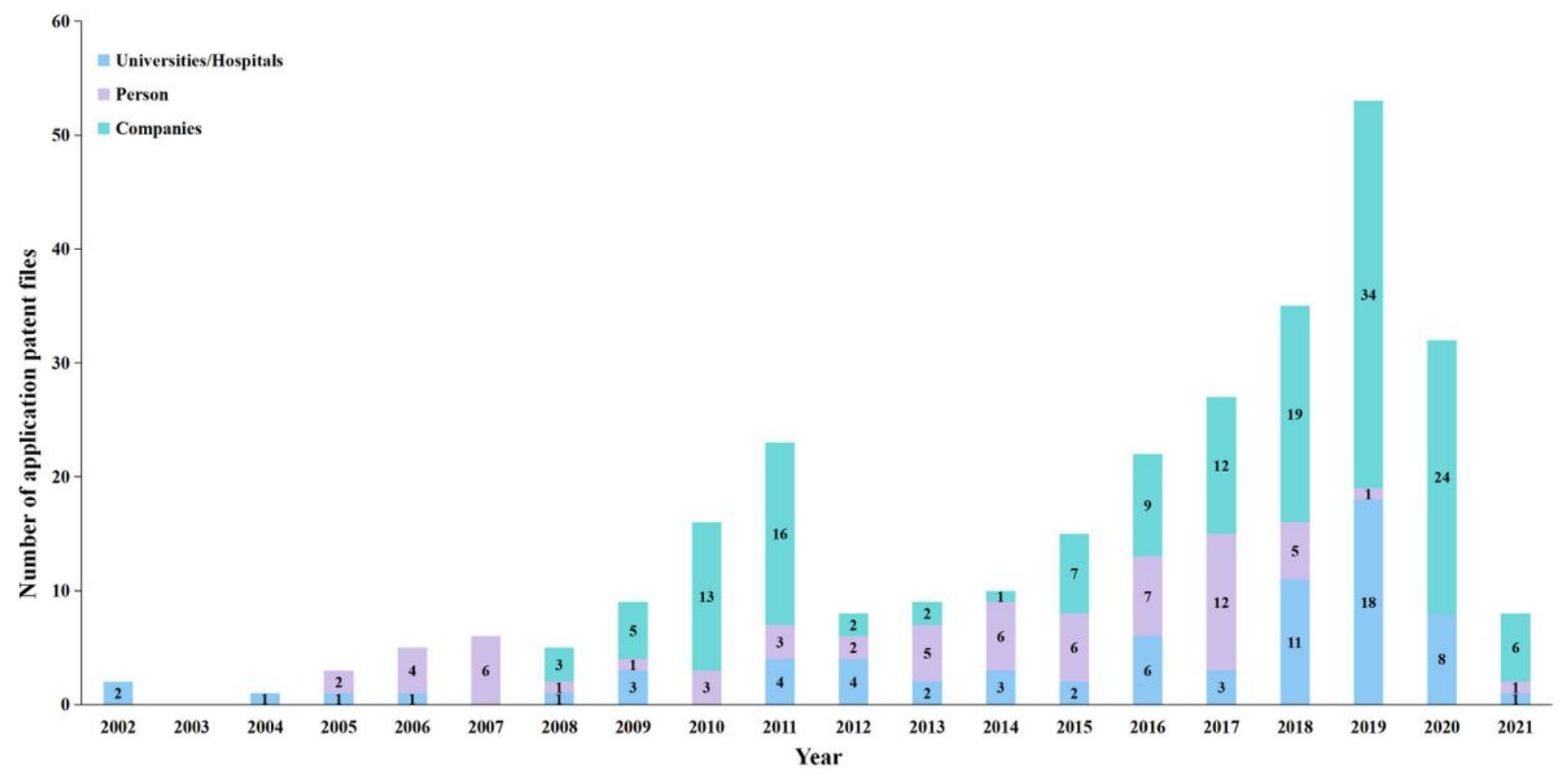

\section{Figure 3}

The number of patent applications by different types of assignees. Different colors reflect different sorts of assignees.

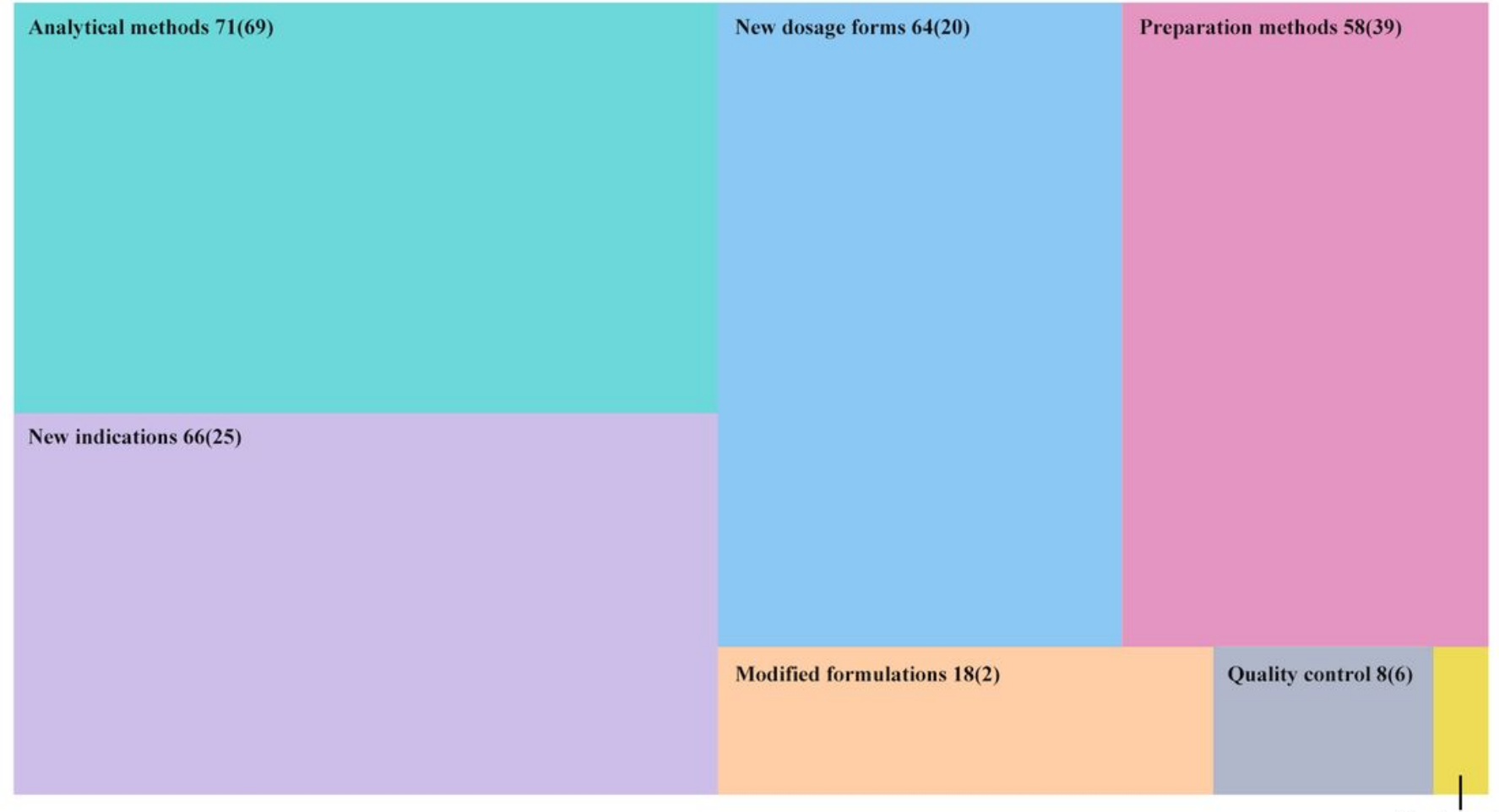

Equipment 2(1)

\section{Figure 4}

Patents of different technological classes. Figures outside brackets indicate the number of all patents, whereas figures inside brackets indicate the number of alive patents. 


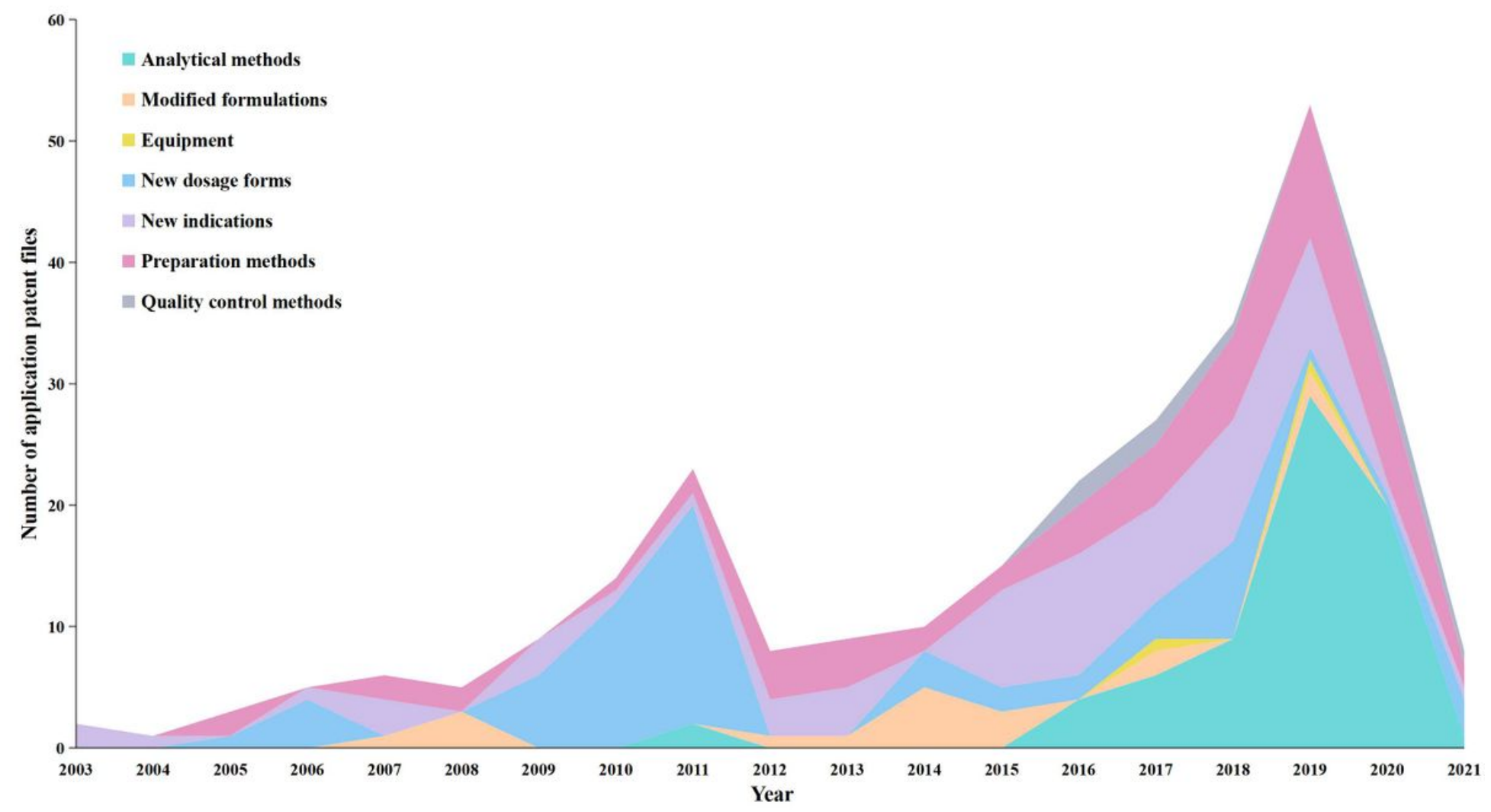

\section{Figure 5}

Time trends of patent applications in different technological classes.

\section{Supplementary Files}

This is a list of supplementary files associated with this preprint. Click to download.

- Figures1.docx

- FigureS2.docx

- FigureS3.docx

- FigureS4.docx

- TableS1.docx 